\title{
The Research on College Student's Employability Teaching Model Based on WEB3.0
}

\author{
Xiang Fei \\ School of Business Administration, QILU University of Technology, Jinan, P. R. China \\ xf99992608@126.com
}

Keywords: WEB3.0, College student, Employability, Teaching model.

\begin{abstract}
This study combined with the situation of college teaching information technology developing in WEB3.0, from view of user's using and satisfying, on the basis of defining college students' motive of WEB3.0 adopting in employability learning situation, embraced the effect of WEB3.0 adopting on college students' employability teaching model innovation, explored the teaching method reform and practice conforming to college's information technology situation, so as to innovate the "constructive" employability teaching model based on WEB3.0 and promote college student's learning interests and college's teaching quality.
\end{abstract}

\section{Introduction}

Employability is the decisive factor to decide success or failure of one's career, and employability cultivating of college student is very important, which needs to design the teaching model on the basis of the situation of employability learning. Past studies show that the teaching model based on modern information technology has great positive significance on college's teaching. Modern information technology usually indicates information communication technology in the medium of Internet, which creates, diffuses, stores and manages information, up till now, which goes through WEB1.0, WEB2.0, WEB3.0,WEB4.0. The characteristic of information value gaining of WEB4.0 makes its developing and using prone to B2C and B2B, while comparing to defects caused by web network ethic problems of WEB1.0 and WEB2.0, WEB3.0 establishes "WEB library" on the basis of total WEB sources, which effectively realizes knowledge sharing, whose IM system is a technology platform in knowledge circles, and reflects instantaneity of teaching ${ }^{[1]}$. Focusing on importance and urgency of the above academic and practical value, this study explored the education information technology platform in WEB3.0 that can meet the requirement to develop employability from individual inherent motive and necessity of choosing WEB3.0 in the situation of employability developing, and put forward some guides that are beneficial to college student's employability teaching reform and practice.

\section{Theoretical Basis}

In the study of employability, college student's employability is very important topic. In the past, people usually judge student's learning result or college's education status by valuing student's test score, while now, student's employment situation and employment rate become more and more important ${ }^{[2]}$ British studies clearly highlight only having corresponding skills is not enough, but if really playing a role in the employment or apply for a post is crucial, which needs to make student's employability cultivating involve into college's teaching. The Nottingham Trent University's Careers Advice and Employment Service (CAES) gave in-depth explanation to college student's employability cultivating. CAES thought that employability skills include positivity, creativity, organizing skill, interpersonal/social skill, problem-solving and leading skill. Nabi and Bagley made college student's employability divide into three aspects, which are individual skills (motive, organizing, team-working, interpersonal/social, leading), communicating skills (written, verbal and nonverbal) and problem-solving skills (positivity, creativity, decision-making) ${ }^{[3]}$. These days, the points of American Society of Training and Development (ASTD) could be the representative ones in the world. ASTD put forward that college student's employability teaching include basic skills 
(reading, writing, calculating), communicating skills (listening, speaking), adaptive skills (problem-solving, creative thinking), developing skills (self-esteem, motive, goal-setting, career design), group-establishing skills (social, team-working, consulting) and influencing skills (understanding organizational culture, leading) ${ }^{[4]}$.

From the above theoretical analysis, past studies all highlighted basic skills (listening, speaking, reading, writing), thinking skills (learning, creating), social skills or team-working skills, individual characteristics (responsibility, self-esteem, et al.). Those studies gave referencing outline for the study on Chinese college student's employability teaching model.

\section{Combination of WEB3.0, Employability and College Student's Teaching Model}

Information technology application in WEB3.0 mode is of some characteristics including user generated WEB content, large information, community gathering, greater participation, encouraging developing and communicating in real-time, and its characteristic of sharing information closely grasps real needs of social and cooperating among college students, teachers and classmates in the class and outside group with common interests, which is good for college student to realize the goals of positive learning ${ }^{[5]}$. At the same time, network is no longer a teaching information transmission medium for college students, but is a comprehensive platform of constructive learning. In which, WIKI and BLOG are the most extensively used in the teaching situation. To teaching practice, WIKI specially has advantages in knowledge system establishing, group operating and project running, properties of collaborative writing, simple format and convenient links, asynchronous records, version back and change tracking of WIKI are beneficial to students to share and collaborate. While BLOG used to record learning log or express opinion, which has clear advantages in interactive and real-time aspects ${ }^{[6]}$, and facilitate teacher and student to communicate learning experience by the message and reply, give student more opportunities to speak thinking and exercise writing. In fact, information technology in WEB3.0 caters to constructive learning idea to some extent. Constructive learning highlights knowledge constructing, positive learning, student-centered and communicating instantly. Nowadays, WEB3.0 technology in the situation of teaching is still on exploring phase, scholars are still studying in WIKI, BLOG and WeChat, theoretical construction, practice experience and college teaching reform research on grafting WEB3.0 technology in employability teaching model are scare. In fact, college students are likely to have obvious psychological distinction between "life" information technology and "education" information technology. Information technology only meets requirement of teaching, its effect in learning situation depends on not only the contribution to the teaching function, but individual characteristics of college students, for example, the attitude being inclined to adopt information technology in learning situation. So college students' motive to adopt WEB3.0 technology to employability learning is just direct factor of driving their learning process. Then holding this kind of positive effect of psychological motive on learning result, and setting up WEB3.0 factors from discipline constructing, curriculum designing, teaching platform developing could establish employability teaching model in all-dimensional for college students.

\section{Summary}

This study focuses on the teaching method reform and practice of employability cultivating in WEB3.0 model, studying conclusions will be convenient for teachers to mix curriculum content of "project, case, problem" together with innovative teaching model of "constructive teaching on the basis of employability cultivating", which is specially suitable for the curriculums adopting project-operating, case teaching and interactive discussion, and gives some suggestions for college student's employability teaching model based on WEB3.0 from the following aspects: the first, confirming college student's motive to choose WEB3.0 in the situation of employability developing. Discriminating college student's motive to choose WEB3.0 in the situation of employability developing, and positively exploring the effect on constructive teaching model based on employability cultivating; the second, confirming positive meaning of WEB3.0 adopting on 
constructive teaching model based on employability cultivating. By teaching face to face, comparing with students choosing WEB2.0, deeply understanding the effect of WEB3.0 adopting on constructive teaching model based on employability cultivating; the third, setting up constructive teaching information technology platform based on college student's employability cultivating. Excavating innovation paths adopting teaching information technology, and creating constructive teaching information technology platform being beneficial to college student's employability teaching reform and practice in WEB3.0.

\section{Acknowledgement}

This research was financially supported by Teaching Reform Project of QILU University of Technology (Grant NO. 201625), China Postdoctoral Science Foundation (Grant NO. 2015M571266), Humanities Social Science Project of Education Ministry (Grant NO. 16YJC630143), National Education Science Plan "Key Project of Education Ministry" (Grant NO. DIA150293), Humanities Social Sciences Project for Universities of Shandong (Grant NO. J15WB01), Plan of Supporting Outstanding Young Scholar in Humanities Social Science of QILU University of Technology (Grant NO. SKRC15-01), National Undergraduate Training Project for Innovation-Entrepreneurship of QILU University of Technology (Grant NO. 201610431054), Key Project to Statistical Research of Shandong (Grant NO. KT16235)

\section{References}

[1] Wu Hongyue, Du Yuyue, A logical petri net-based approach for web service cluster composition, Chinese Journal of Computers, vol.38, pp. 204-218, 2015.

[2] Xie Jinyu, Song Guoxue, An analysis on the students' possible employment and their useable skills after education, Nankai Journal (Philosophy, Literature and Social Science Edition), vol. 2, pp. 85-92, 2005.

[3] G. R. Nabi and D. Bagley, Graduate's perceptions of transferable personal skills and future career preparation in the UK, Career Development International, vol. 3, pp. 33-47, 1998.

[4] H. F. O' Neil, Jr. K. Allred and E. L. Baker, Review of workforce readiness theoretical frameworks, Int. O’N eil, H. F. Mahwah, Jr., Workforce Readiness, Competencies and Assessment, Lawrence Erlbaum Associates, 1997.

[5] A. L. Feller, T. Wu, D. L. Shunk, et al., Petri net translation patterns for the analysis of business collaborators messaging protocols, Int. IEEE Transactions on Systems, Man, and Cybernetics, Part A: Systems and Humans, vol. 39, pp. 1022-1034, 2009.

[6] Du Yuyue, Jiang Changjun, Zhou Mengchu, A petrinet-based model for verification of obligations and accountability in cooperative systems, Int. IEEE Transactions on Systems, Man, and Cybernetics, Part A: Systems and Humans, vol. 39, pp. 299-308, 2009. 